\title{
Advanced Banking for Digitalization in Animal Husbandry
}

\author{
Milvina Terzieva ${ }^{1 *}$, and Dimitar Karastoyanov ${ }^{1}$ \\ ${ }^{1}$ Institute of Information and Communication Technologies - Bulgarian Academy of Sciences, 1113, \\ Acad. G. Bonchev str. B1.2, Sofia, Bulgaria
}

\begin{abstract}
The article describes ICT innovations in modern banking and the transition to open banking. Platforms for fast money transfers, movement schemes for transactions and types of services are presented. Possibilities for digitalization of financial operations in animal husbandry are discussed. Factors such as reducing costs, increasing efficiency, facilitating and improving decision-making in the overall management of the financial, economic and reporting activities of a livestock farm are analyzed.
\end{abstract}

\section{Introduction}

The epicenter of the evolution of banks in the Internet age is the convergence of banking and telecommunications operators, as well as Internet service providers and web portals, [1], [2]. Conventional consolidation within the industry, which has occupied the telecommunications and banking sectors over the last few years, continues, and atypical partnerships for communications and financial services aimed at creating new forms of competition are accelerating.

Banking innovations are perceived as the end result of innovation activity, specific financial innovations carried out by banks on the financial markets or in their own activity in the form of a new and improved product, service or process.

An innovation is any novelty in all spheres of the bank's activity, having a certain economic or strategic effect, the application of which can provide growth of the bank's clients, increase of the market share, reduction of the expenses for each of the activities or creating conditions for the listed. The innovation process, i.e. the process related to the creation, development and dissemination of innovations, covers all aspects of the bank's activity - from the development of a concept or idea to its practical implementation.

IT services for banks are vital for every process. Digitalization is not an unambiguous concept with the use and availability of IT processes in a bank, but rather is related to the way end customers interact with the particular institution, whether they can do it remotely, and how digital processes are included in the service them in an offline environment - in a bank office. Part of the digitalization process is also the banks' efforts to reduce paper, which also affects the environmental point of view. Digitalization is helping the banking sector to provide a new type of service to its customers that they can use more and more accessible, faster and more conveniently in their daily lives, as well as in situations where it was not

\footnotetext{
* Corresponding author: msalabasheva@yahoo.com
} 
possible before. Innovations develop in every area in which the bank operates - in payments, in lending, in the management of savings and investment products. For payments, for example, a person can rely on money when he is abroad from his bank card. However, when he loses it and has no extra with him, nowadays he can order an express transfer of his name (for example, Western Union) from his smartphone, which he can withdraw in cash literally in a minute from the nearest location in the respective country. Similar may be the benefits of digital services, helping a person in unforeseen situations in any area.

Banks are in a race to be able to provide the first, best, most innovative and most efficient service, hoping that this will grab the attention of consumers. Non-banking institutions as well as Fintech companies are also involved in this competition, which accelerates and strengthens competition in digitalization, [3]. By providing services and processes for remote work of customers with banking systems - use of services, ordering new products, managing their funds, banks will rely on an increasing percentage of customers to start banking on this not new (because developing over 10 years), but a modern way today. Trends show that the development of digitalization is the future, and some of the digital processes lead to increased efficiency for the bank (operating cost relative to income). The trends in the banking sector are also for optimizing the cash turnover and its migration to non-cash methods of payment.

Sending and receiving money has become much easier. This not only made it easier to manage periodic payments, but also allowed small businesses without physical shops (e.g. small farmers, agricultural and livestock producers, and sole traders) to appear almost anywhere. There are already many merchants who allow online payment, as well as to set up a recurring payment, and accordingly it can be stopped very easily. In addition, businesses can now operate entirely online. Merchants can even attend conventions to sell goods and use services such as Western Union, Venmo and PayPal to receive payment.

\section{Open banking}

To cope with growing IT requirements and better innovate their customer services, many large banks have launched large-scale digital transformation projects worth hundreds of millions. The pace at which financial institutions are embracing cloud platforms is accelerating and is a symbol of the strong intentions of sectors to rely on this technology for the foreseeable future, [4], [5].

Open banking is growing in Europe. The concept of open banking has been central to the financial services dialogue for many months, fueled in part by the accumulation of the revised EU Payment Services Directive. Open banking is a model based on the exchange of bank data between two or more non-aligned countries in order to provide improved market opportunities.

Switching to open banking allows the provider to be authorized as an Account Information Service Provider (AISP), which means that it can now use the banks' Application Program Interface APIs securely.

To offer added value to end customers and competitive prices of services, the Account Base Money Transfer (ABMT) solution is integrated into the core system of a digital or banking giant. This type of ABMT is a solution for offering real-time money transfer services and can be integrated into their existing sales system. This solution is aimed at financial institutions that want to expand their business by expanding their money transfer and repayment capabilities using their partnership with a fast money transfer provider. ABMT allows customers to send money to countries and territories through the provider's extensive network by paying the money in cash and into accounts (APN) and paying it from an account (bank or wallet). This will increase the trust in the brand and its competitiveness.

ABMT is the ability to send money directly from the sender's bank account to be paid in cash within minutes at any location in the partner network around the world or directed by 
the recipient to be credited to his bank account. This allows bank users to send money transfers through various banking channels such as online banking, bank branch locations, telephone banking, mobile banking, ATM.

\section{Integration of platforms for fast money transfers in banking systems}

Let's look at how a platform for fast cash transfers, for example Ideal, can be integrated into a bank core system. ABMT enables partners to own, manage and control the ultimate customer experience for transactions using the Ideal platform and network. Customers will benefit from this by quickly sending money in minutes directly from their bank accounts. The money can be sent directly from or received directly in their bank account. In addition, both the bank's customers and customers who are not its customers can conveniently visit an Ideal location to make money transfers. At the same time, the bank controls the cash flow and the services it sells. By accessing Ideal's global network, the bank will benefit from new customers, competitive services and prices, add a new service for transfers / payments to users with a truly global reach and avoid numerous intermediary fees and deductions from the beneficiary.

Here the Internet service provider (ISP) plays a very important role. It ensures the communication of the main server communicates with the Internet Service Provider (ISP). This is a portal (Gateway) through all networks available to the cardholder / accountholder based on a centralized database system.

Ideal Gateway enables third parties to expand the Ideal money transfer service to bank customers and cash registers. Based on the existing Ideal Money Transfer service, through Ideal Gateway customers can easily send and receive money through various means such as the bank's hosted website, ATM location and mobile offer. The money can be sent directly from or received directly to the user's bank account. In addition, customers and noncustomers can conveniently work with branch cashiers working as Ideal Authorized Agents to make money transfers. Partners can take advantage of Ideal global Agent's extensive network to provide their customers with unparalleled flexibility in sending and receiving money.

Ideal Gateway uses standard protocols and data structures to communicate with partners. The system exposes an XML document and SOAP interfaces via HTTPS, through which all the details of the requested transaction are transmitted. All communication between the parties is done through an XML document / SOAP request sent to an HTTPS endpoint using the POST action. The assigned SSL client certificate must also be sent as part of this request. The responses to the requests are returned synchronously to the same link from which the request originated. Each response will contain standard HTTP response codes along with an XML response document. (Fig. 1).

All Ideal Services money transfer transactions, such as sending and receiving money, are classified as originating from a specific type of domain. The domain is a broad summary of how the transaction is performed. The classification of domains is used in the authorization of orders, price transactions, validation of compliance requirements, conducting business analysis and in detecting and investigating fraud.

The $<$ device $>$ tag is used in the XML message to distinguish whether transactions are from physical, electronic, or customer service domains. The token value represents the Domain from which the message was sent.

Fig. 2 shows the list of domains, as well as the possible Device Type values specific to each Domain. 


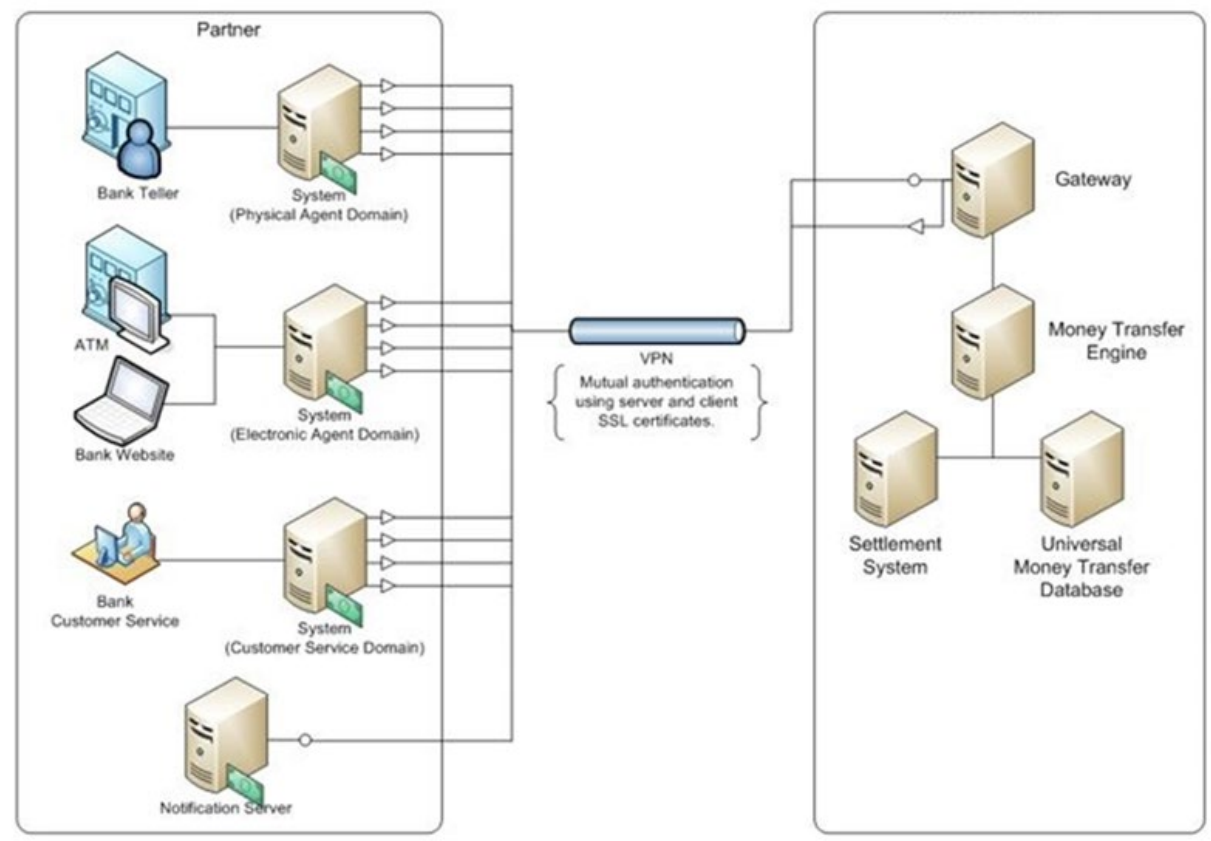

Fig. 1. Scheme for the movement of requests and responses

\begin{tabular}{|l|l|}
\hline Domain & Possible Values for Device Type \\
\hline Physical & AGENT, RETAIL \\
\hline CSR & CSR \\
\hline Electronic & ATM, WEB, IVR, MOBILE \\
\hline
\end{tabular}

Fig. 2. Types of domains and possible values

Ideal Gateway services can be categorized into three types of domains: Physical Agent, Electronic Agent, and Customer Service.

Physical Agent Domain - represents those transactions that involve an associate partner acting as an Ideal agent. For example, a bank cashier of a partner or similar situations at points of sale, where the cashier will perform the transaction on behalf of the customer (incoming customers, existing and new):

- SEND MONEY IN CASH - Each client, whether an existing partner or not, can choose to send a standard money transfer to Ideal using one of the partner's associates at the branch location. This process is only supported in the physical domain.

- RECEIVE MONEY IN CASH - Each client, whether an existing partner client or not, can choose to receive a standard Ideal money transfer using one of the partner's associates in a branch. This process is only supported in the physical domain.

Sending money can be done with the help of Ideal Card in both electronic and physical domains.

Electronic Agent Domain - represents those transactions that are performed directly by the client using one of the electronic or automated systems of the partner. For the use of such systems it is assumed that the user is an existing client of the partner and has previously opened an account and has registered / registered with the partner. Most self-service scenarios would be classified as an electronic agent domain, including those running using a network, ATM systems, IVR (telephone), Self-service Kiosk, and mobile channels. 
- SEND MONEY FROM BANK ACCOUNT - An existing partner's client can choose to send money directly from their account to an individual recipient via Ideal. Once saved, the money transfer is available to the recipient using one of Ideal's standard payment services. This process is only supported in the electronic domain.

- RECEIVE MONEY IN BANK ACCOUNT - An existing partner's client can choose to receive a standard Ideal money transfer directly to their account. This process is only supported in the electronic domain.

Customer Service Domain - represents those transactions that are performed by customer service representatives of a partner using API calls.

- MANAGE TRANSACTIONS - CANCEL, SUSPEND AND RESUME - A partner's customer service representative can manage certain aspects of the remittances made by the partner. Remittances may be canceled altogether or suspended, and may not be paid until they are resumed.

If the electronic domain is to be implemented, it is assumed that the partner agent has an existing electronic environment.

The banking partner must integrate with Ideal Money Transfer using Ideal Gateway therefore there is a relationship between Ideal and the banking partner in order to successfully implement the money transfer solution in the bank's acceptance system.

All transactions sent via Ideal, regardless of the creation method, are stored in a special database called the Universal Data Transfer database. Transactions remain in this database on hold until they are paid to the user or exceed 365 days. All pending transactions can be paid for using any of Ideal's existing systems or services.

As an example, a customer may send a money transfer from their mobile device to another customer's mobile device. However, the receiving customer may choose to receive the money on the spot at an Ideal agent. Although it was originally intended for mobile payments, this transaction was actually paid in cash.

The normalizing factor for all remittances is that they are always available to be paid in cash to an agent. This allows the sender not to be obliged to determine the method of payment to the recipient; he simply puts it in the database as a money transaction. Similarly, the recipient should not be interested in the origin of the remittance; he simply receives a money transfer from the call database using the method he has chosen.

The two main processes supported by the banking system are the Sending Money process and the Money Receiving Process. As described above, all money transfers are stored and retrieved from the same database.

\section{Digitization in animal husbandry}

Open banking and fast money transfers aim to support the process of accelerated digitization in animal husbandry, which will allow farmers to take advantage of the competitive advantages of ICT technologies, such as reducing costs, increasing efficiency, facilitating and improving decision-making. in the overall management of the financial-economic and reporting activity, [6].

Since most of the breeders are not ICT specialists, it is good to develop a complete computer model of the operation of a livestock farm. The interaction with the model should be as easy and user-friendly as possible. The main modules in this model can be:

- Estimated income, expenses and losses model,

- Analysis of historical data on various grounds,

- Management algorithms analyzing variable and fixed costs,

- Algorithm for determining the correct model for reinvestment,

- Creating a database for monitoring and analysis of system parameters,

- Development of models for decision making according to atmospheric conditions. 
For intelligent functional solutions and financial management of the livestock farm, it is good to consider creating and using the following models:

- models for functional solutions of budgeting cash flow,

- capital investment model (purchase / lease) for a livestock farm,

- model for analysis and assessment of the financial stability of a livestock farm,

- intelligent solutions for innovative activity in the livestock farm.

Innovation, including ICT, has been identified as an engine of economic growth, a key factor in increasing the competitiveness of industrial enterprises. The economic benefits and competitive advantages for enterprises from the creation, introduction and use of innovations are recognized and proven in the literature, [7]. On this basis, the impact of the costs of innovation activity on the company results and characteristics of livestock farms can be assessed.

\section{Conclusion}

The synergies resulting from the partnership between telecommunications operators and banks provide new opportunities to offer more and more products and services to consumers, as well as to facilitate their financial interactions with them. Given the general threat of alternative solutions or providers, banks and telecoms operators must look for opportunities for partnership and full use of these areas of convergence.

This is especially useful for small farmers of vegetables, fruits, meat and milk. Despite their large numbers, few are good experts in digital technology and financial management. Therefore, it is important for this category of consumers to have easy and fast access to many understandable services for organizing their economic activity.

ICT in animal husbandry using the resources of modern banking will make the entry of this industry into the 21 st century faster and easier.

The research leading to these results has received funding from the Ministry of education and science under the National science program INTELLIGENT ANIMAL HUSBANDRY, grant agreement $\mathrm{N}$ Д01-62/18.03.2021

\section{References}

1. D. Weatherford, History of the money, Obsidian, 286-290 (2001)

2. E. Sekulow, Industry Opinions: Telecoms in the 1990s, (Comm. Int'l, Oct. 1991, 49, 1991)

3. Office of Tech. Assessment, U.S. Congress, U.S. Banks and International Telecommunications 19 (Background Paper No. Ota-Bp-Tct-100, 1992) [Hereinafter Office of Tech. Assessment] (1992)

4. Gartner Forecasts Worldwide Public Cloud Revenue to Grow 17\% in 2020, Press Releases, STAMFORD, Conn. November 13 2019, https://www.gartner.com/en/newsroom/press-releases/2019-11-13-gartner-forecastsworldwide-public-cloud-revenueto-grow-17-percent-in-2020 (2019)

5. RightScale STATE OF THE CLOUDREPORT from Flexera (2019), https://resources.flexera.com/web/media/documents/rightscale-2019-state-of-thecloud-report-from-flexera.pdf

6. A. M. Malz, Financial risk management: models, history, and institution: models, history, and institution, (John Wiley \& Sons, Inc., 2011)

7. E. Aggelopoulos, N. Eriotis, A. Georgopoulos, A. Tsamis, J. Account. Taxation, 8(4), 40-50 (2016) 